\title{
RESPONDING TO AN INCOME SHOCK THROUGH INCREASING FOREST EXTRACTION: SURVEY EVIDENCE FROM ETHIOPIAN COFFEE FARMERS ${ }^{1}$
}

\author{
Degnet Abebaw ${ }^{2},{ }^{*}$, J ohn Mburu ${ }^{3}$, Karin Holm-Müller ${ }^{4}$
}

\begin{abstract}
The worldwide turndown in coffee revenue to the majority of resource poor primary producers has become a serious threat to sustainable development. There is however inadequate knowledge with respect to mechanisms used by resource poor coffee farmers to stave off situations of economic hardship. Using cross-sectional household survey data from southwest Ethiopia, the present study investigates whether or not farmers use forests to even out variability associated with risky coffee income. A zero-inflated negative binomial model was used to explain farmer frequency of firewood collection trips as a response to income shock and risk in coffee farming. The empirical results indicate that a rise in household forest extraction effort for firewood is strongly associated with shortfalls in current coffee income and with income uncertainties prevailing in the coffee sector. The study draws policy implication from the perspectives of development and environment.
\end{abstract}

Keywords: Income shock; coffee farming; forest extraction; Ethiopia, Africa

\footnotetext{
${ }^{1}$ The final version of this article was submitted in March 2009.

${ }^{2}$ Ethiopian Economic Association/Ethiopian Economic Policy Research Institute, P.O. Box 34282, Addis Ababa, Ethiopia

* Corresponding author:

E-mail: degnet2003@yahoo.com; Tel. No.: 0116-453200; Fax No.: 0116-453020

${ }^{3}$ Center for Development Research (ZEF), University of Bonn, Walter-Flex Str. 3, D-53113 Bonn, Germany

${ }^{4}$ Institute for Agricultural Policy, Market Research and Economic Sociology

University of Bonn, Nussallee 21, D-53115 Bonn, Germany
} 


\section{Introduction}

Worldwide, coffee farmers are typically confronted with low and unpredictable coffee income (ICO, 2004; Ponte, 2002; Vakis, Kruger, and Mason, 2004; Varangis, Siegel and Lewin, 2003). Most of these studies show that the main sources of vulnerability to coffee income risk include, inter alia, fluctuation of green coffee prices, crop diseases and pest attack, government policies and legislations, and weather-related factors. Exposure to risks and adverse income shocks in developing countries, including Ethiopia, leads to declines in farmers' well-being due to the lack of well-functioning insurance and credit markets to smooth consumption when income falls (Maitra, 2001; Morduch, 1999, Dercon, 2002).

Given this state of affairs, individuals and households in the developing countries of Africa, Latin America and Asia keenly explore self-insurance mechanisms to counteract these shocks (Alderman and Paxson, 1992; Dercon, 2002). For example, individuals (households) may engage in activities such as crop diversification (Fafchamps, 1992), off-farm employment (Rose, 2001; Mishra and Goodwin, 1997; Rose, 2001), intercropping (Godoy and Bennett, 1991), or spread their crop sales over time (Goodwin and Kastens, 1996) to reduce the risk of facing variable income, ex ante. Further, they may resort to borrowing (Udry, 1995), asset sales including livestock and land (Rosen and Masset, 2003; Rosenzweig and Wolpin, 1993), past savings (Deaton, 1990), out-migration and remittances (Rosenzweig, 1988), temporal off-farm work (Kochar, 1999) or pull children out of school to work (Jacoby and Skoufias, 1997) to smooth consumption ex post, albeit imperfectly. However, at the present, there is a paucity of relevant information about the mechanisms used by the small coffee farmers to deal with income risk ex ante or address adverse income shocks ex post (Vakis, Kruger and Mason, 2004).

This paper provides an impetus to test the hypothesis that farmers use forests as a safety net by increasing the supply of their family labor for the extraction of firewood. 5 Our study differs from most of the previous studies in several ways. First, previous studies largely focused on sources of production or market risks or of fluctuations in yield or price separately. In contrast, the present study focuses its attention on income risk since it appears to be more important than just yield or price risks for a cash crop (coffee) producer. Second, we give an explicit account of how a farmer's subjective rate of time preference apart from socioeconomic and demographic factors alters his/her

\footnotetext{
${ }^{5}$ As a reviewer pointed out, we also recognized that, as in other countries, forests are important sources of food, medicine, timber, and other ecosystem services in Ethiopia. However, our exclusive focus in this paper is on its importance as a risk coping strategy in the study areas.
} 
forest extraction and risk coping behavior. Furthermore, we specify and test the effects of a wide range of other risk coping mechanisms in rural areas including inter alia membership to a farmers' group, off-farm employment, crop diversification, and social-ties or demographic history.

The empirical data for the study were drawn from a cross-sectional survey of 195 coffee farmers in Yayu and Gewata districts in southwest Ethiopia. The study sites border with the de jure mountain forests of southwest Ethiopia. There are several reasons as to why Ethiopia is an important case for the present study. Firstly, Ethiopia is one of the coffee producing countries most affected by recent downturn of green coffee prices (Oxfam, 2002). ${ }^{6}$ Second, smallholder farmers produce over ninety five per cent of Ethiopian coffee, ${ }^{7}$ using on average less than a hectare of land (Tessema, 2001). Third, Ethiopia is one of the poorest countries in the world and the vast majority of farmers in rural areas tend do not have adequate access to essential services such as credit, education and agricultural extension. Likewise, rural insurance markets are missing (Dercon, 2002). Essentially, it would be in the farmers' interest to self-protect their welfare against income risk with their own scarce resources and knowledge. Fourth, coffee is the main agricultural investment and also a prime source of cash income to estimated 700 to 800 thousand farmers in Ethiopia. The outcome of uncertain events, thus, can make the difference between survival and starvation (Ellis, 1993). Finally, in southwest Ethiopia a large number of small coffee farmers are located close to remaining mountain forests, which among others used to provide a natural habitat for populations of wild Coffea arabica and other biological resources (Agrisystems Limited, 2001).

Evidence presented elsewhere indicate that forests are used as buffer stocks to farmers and most of these studies are of the opinion that forest conservation strategies success requires an improvement of farmers' ability to mitigate risks (Fisher and Shively, 2003; Reardon and Vosti, 1995; Takasaki et al., 2004). Thus, the outcome of this study would be useful to policy makers and governments in guiding their efforts in integrating development strategies with forest conservation objectives.

The rest of this paper is organized as follows. In Section Two, we outline the theoretical framework and derive key hypothesis of the study. In Section Three, the empirical model to estimate the impact on forest pressure of coffee income risk and other variables is specified. Section Four describes the survey procedure and source of data used for this study. Section Five then presents the results and discussion of the study

\footnotetext{
${ }^{6}$ For instance, in 2001 Ethiopia's export income suddenly declined by forty-four percent from the previous year, despite the fact that exported volume remained on the rise.

${ }^{7}$ The type of coffee variety cultivated in Ethiopia is Coffea arabica.
} 
by mainly focusing on the socioeconomic profile of the sample households and the determinants of their forest extraction behavior. Conclusions and policy implications of the paper is given in Section Six.

\section{Conceptual framework and hypothesis}

Adjustment in labor use via resource extraction has been one of the key behavioral responses to an income shock among poor rural households in developing countries (Baland and Francois, 2005; Byron and Arnold, 1999; Fisher and Shively, 2003; Pattanayak and Sills, 2001; Takasaki, Barham and Coomes, 2004). There are several reasons why asset-poor households in rural areas turn to draw upon forests as a safety net. First, besides requiring labour, forest extraction demands physical capital (ibid.). Second, tropical forests are biodiversity-rich hot-spots such that they provide a wide range of opportunities for exploitation by humans. Third, labor productivity allocated to common-pool or open-access resources such as forests is relatively homogeneous in comparison with productivity outside (Baland and Francois, 2005). It is for these reasons that governments make efforts to protect these forests from rapid exploitation by humans even though, in fact, they often are de facto open access resources.

For low income households facing widespread market imperfections in rural areas of developing countries (de Janvry, Fafchamps and Sadoulet, 1991), activity choice cannot be fully understood without due consideration of consumption preferences and tastes (Singh, Squire and Strauss, 1986). The implication of this is that asset (natural, physical, social, human and financial) endowments matter to one's choice of livelihood activities and risk coping strategies (Reardon and Vosti, 1995; Ellis, 1998).

The decision problem of a farmer is to maximize the expected utility. In this framework, it is presumed that a household forms rational expectation and that it is confronted with coffee income risk. We also explicitly split the agricultural period into wet and dry seasons to set up a farmer's farm management plan under risk. In the wet season, the farmer fully realizes risk outcomes from the previous dry season, but yet remains uncertain regarding outcomes of its current input use decisions, including labor, in the coming dry season. In other words, the farm households' reaction to risk in the wet season depends on both the state of realized event in the previous season and the expected decision outcomes in the next season. Household participation in forest extraction is seen as a safety net, and may therefore be associated with a host of farm and farmer characteristics, location, and infrastructure, since farmers do not have an insurance market or lack adequate access to consumption credit. As a result, solving the constrained maximization problem subject to budget and time constraints, the 
reduced form equation for a farmer's labor supply in the forest extraction can be specified as:

$$
L_{f}=l\left(P_{f}, r, R, Z, \Theta_{l}, \Theta_{0}\right)
$$

where, $L_{f}$ is the optimal amount of forest extraction labor used by the household in the wet season; $P_{f}$ is price of a forest good gathered; $r$ is a wage rate; $R$ is a vector of household characteristics; $Z$ is a vector of infrastructure and location attributes; $\Theta_{1}$ is an indicator of riskiness of coffee income; and $\Theta_{0}$ is an indicator of shortfall in coffee income. Controlling for other differences, the equation specified above predicts that forest extraction trip, a proxy for effort, is associated with shortfalls of coffee income and its exposure to risk. Proxies are used for some of the variables which are included in the reduced for equations. For instance, the variable $P_{f}$ is not used due to lack of adequate variation in the cross-section. Instead, it is proxied by the distance to the nearest road. Distance to the nearest forest and education of household head are assumed to bear a direct relationship with the opportunity cost of time spent in the forest extraction activity. It is also worthwhile to note that participation in a paid off-farm employment in the previous season may predict risk management or risk coping in the current season via labor market participation thereby increasing the opportunity cost of labor in forest extraction, all else equal.

The key interest of the paper is to test the hypothesis that coffee farmers use forests as a safety net to recoup adverse income shocks and as a precautionary tool against future uncertain income. A host of other variables such as households' time preferences, resource endowments, location and demographics are incorporated into the model so as to capture household differences in risk management and risk coping on the one hand and to account for other motives for undertaking forest extraction on the other hand.

\section{Empirical methods}

To empirically test the theoretical relationship specified in the previous Section, data on household frequency of firewood collection in the wet-season are used. The dependent variable is constructed by eliciting the total number of trips made by the household to collect firewood from the nearest de jure state forests. Stated in other words, the dependent variable takes a non-negative integer values and hence a count data. As suggested by Gurmu and Trivedi (1996) a Poisson regression is a good starting point to 
analyze data of this kind. In analyzing data by a count data model, one may have to account for different data generating processes within one particular count, not compatible with a standard count data model (Melkersson and Rooth, 2000). The most common feature of this kind is a relative excess of zeros (e.g. Gurmu and Trivedi, 1996). As will be discussed later in this paper, our forest extraction data manifest clear signs of over-dispersion and high incidence of zero observations, violating key assumptions of the Poisson model. As a result, we turned to use a zero-inflated negative binomial regression (ZINB) for our estimation procedure (Cameron and Trivedi, 1998; Haab and McConnel, 1996).

In a zero-inflated count data model, zero observations are assumed to originate from two different data generating sources. One source, as represented in this study, arises due to households who have not made any firewood collection effort from the de jure protected forests at the study sites. The other zeros originate from households who reported not having any forest extraction trips in the sample period, perhaps on account of a mere chance, misreporting or shortness of the observation period of the study. In building the ZINB model, a household is assumed to make a two-stage decision: the decision on whether or not to engage in forest extraction, and the decision on the frequency of forest extraction, with a possibility of making no extraction. Logit and negative binomial regression models are, respectively, used to jointly explain these decisions within the ZINB modeling framework.

\section{The study area and data sources}

This study was carried out along the boundary of two mountain forests; namely Geba Dogi and Boginda-Yeba. Respectively, these forests are found in Yayu and Gewata districts (locally called Woredas) of southwest Ethiopia. In these areas, agriculture is the major source of livelihood and coffee farming is the prime source of cash income to many families. Maize, sorghum, and teff $^{8}$ are the main food crops. Livestock, particularly oxen, are a prime source of traction power. Most forests within the region officially belong to the state, even if their exploitation by the local population continues to be commonplace and appear to be on the rise (Beshir, 2002; Tadesse, 2003).

The database for this study came from a random sample of 195 coffee farmers (115 from Yayu and eighty from Gewata) in southwest Ethiopia. The field survey was carried out between August 2002 and January $2003 .{ }^{9}$ Semi-structured questionnaires and

8 Teff (Eragrostis abyssinica) is a cereal crop, a staple food in Ethiopia (particularly in the Urban areas) and indigenous to Ethiopia.

${ }^{9}$ This period was an unusually bad year to most of the coffee farmers we surveyed. As a consequence, caution should be made in generalizing household labour allocation decisions which were observed during 
trained enumerators were used to interview respondents. The questionnaire was pre-tested. Respondents were interviewed on a wide range of topics that included basic data on household and individual characteristics, farm characteristics, and demographic history. Furthermore, the dataset contains farmers' evaluation of risk and risk management strategies associated with coffee farming. Respondents also gave their evaluation of the importance of participation in forest extraction as means to stabilize income and to smooth consumption in the face of adverse income shocks involved in coffee farming. Furthermore, data on labor used in gathering forest products over the three months preceding the onset of the survey (wet season in the study areas), were collected, using respondents' recall. ${ }^{10}$

To identify the extent of income risk involved in coffee farming, respondents were asked to define their situation in terms of coffee income in the year 2001/02. The respondents identified this period as the "worst", since it had the lowest income. On the other hand, they rated 1994/95 cropping season as the "best" of the past seven years to the survey period. Respondents were further motivated to report coffee yield and price in these two cropping seasons so that coffee income was inferred indirectly. Respondents were also able to reflect coffee yields and price during normal cropping seasons. As a result, intermediate data on the extent of income shortfalls in coffee farming in 2001/02 was constructed by computing how much additional income could the farmer have obtained had 2001/02 been a normal or typical year. Furthermore, riskiness of coffee income was proxied by coefficient of variation of coffee income and was constructed following the procedure specified by Anderson and Dillon (1992). ${ }^{11}$

our survey period to normal periods and other locations. However, studying farmers' risk coping behaviour requires observing their actual behaviour when such an even unfolds. We are indebted to an anonymous reviewer for pointing out this concern to us.

${ }^{10}$ As a reviewer noted, the reliability of the self-reported data is subject to the usual caveats that apply when responses are based on one's recall. A mixture of strategies was used to minimize (un)intentional over- or under-reporting bias. At the outset, we told respondents that their participation in the survey is absolutely voluntarily and that their identity will be kept anonymous in any analysis of the survey data. Next, in responding to our recall question, respondents were asked to recollect all relevant information about firewood gathering activities by their family members.

${ }^{11}$ Using a triangular distribution function, Anderson, \& Dillon (1992) provides specifications for estimating mean $(E[x])$ and variance $(V[x])$ of crop income given its modal or most likely value $(m)$, the lowest possible $(l)$, and the highest possible $(h)$ as: $E[x]=\frac{(l+m+h)}{3}$, and $V[x]=\frac{\left\lfloor(h-l)^{2}+(m-l)(m-h)\right\rfloor .}{18}$ 


\section{Results and discussion}

\subsection{Summary of the main explanatory variables used in the regression analysis}

The sample households of this study bear heterogeneous characteristics. Table 1 summarizes the main variables used in the regression. On average, household heads in the sample are forty-four years of age. A closer accounting of the data shows that nearly seventy-six percent of the households are native to the study areas whereas the rest (twenty-four percent) migrated to the study areas over the last thirty years. The non-native households comprise of households that originated from central and northern Ethiopia and also from the neighboring and non-coffee growing districts in south and southwest Ethiopia. Those from the central and northern highlands arrived in the 1980s and largely constitute to government-sponsored resettlers in the study areas.

Regarding land, the respondents, on average, hold 2.36 hectares. Of this, nearly forty-one percent is grown with coffee. Land in the study areas belongs to the state and farmers cannot sell it to insulate consumption against adverse income shocks. At the study sites crop diversification is a common practice. For instance, in 2001/02 a typical household in the sample cultivated three different crops, located roughly on four different fields. The survey results also show that households in the sample possess about three heads of cattle, on average. Like in other regions in Ethiopia, agriculture is rain-fed and labor-intensive at the study sites. A typical household in the sample has about six household members. Males head ninety percent of the sample households. Access to formal credit is very limited, and road infrastructure is poorly developed. On average, a household in the sample travels fifty-one minutes and twenty-one minutes to reach nearest forest edge and an all-weather road, respectively. Nearly forty-five percent of the respondents do not have membership to farmers' cooperatives, and, hence, do not have the chance to exercise and benefit from collective bargaining power in the market place. In fact, our field observation indicates that the farmers' cooperatives in the study areas are engaged in various interrelated agricultural activities such as distribution of farm inputs, marketing of farm products such as coffee, lending credit and conservation of natural resources.

The survey results also reveal that forest products are important sources of livelihood in the study areas. For instance, a typical household in the sample had made six round trips of forest extraction in June to August. In fact, this average masks interesting inter-household differences (variance of forest extraction trips $=37.69$ ) existing in the 
sample. About twenty five percent of the sample households did not make any of such trips during the reference period.

\subsection{Perceived importance of some coffee income risk coping strategies}

On average, in 2001/2002 a household in the sample received about 321 Ethiopian Birr and about seventy-four Ethiopian Birr, respectively, from crop and livestock sales. Approximately 256 Ethiopian Birr was earned from coffee sales, which is nearly eighty percent of the crop cash income. What this means is that farmers are disproportionately heavily dependent on coffee. Had the 2001/2002 not been a "bad" year for coffee, this share might have even been higher. Farmers in the sample, on average, had experienced a shortfall of about 1619 Birr from coffee income. The descriptive results also show that farmers on average are exposed to a high level coefficient of variation of coffee income $(40 \%) .{ }^{12}$ Since this result is computed primarily based on recall data provided by respondents, the result should be taken only as a suggestive insight into the issue. What is interesting is perhaps the fact that the result indicates the widespread incidence of heterogeneity in farmers' risk exposure. This may call for differentiated household targeting for risk mitigation and coping policies. Farmers have different perceptions of risk coping strategies. Table 2 provides the list of certain strategies and farmers perceptions towards them. Of the 195 sample respondents, about sixty-one percent of them saw forest extraction as important or very important for helping them cope with adverse income shocks. Out-migration to cities was seen as the least important among the risk coping strategies considered. About seventy four percent of the sample farmers perceive risk coping via livestock sales as important or very important. Similarly, a large number of the sample respondents (sixty eight percent) perceive risk coping through drawing on household savings as relevant. Interestingly, risk coping by pulling out children from school to work was seen as one of the least relevant. A large number of respondents perceive public (government) support as a relevant risk coping mechanism. Reducing food consumption as a risk coping mechanism is seen as important or very important by about fifty eight percent of the sample farmers.

\footnotetext{
${ }^{12}$ Coefficient of variation of coffee income was computed following Anderson and Dillon (1992) with sample data covering seven years preceding the survey.
} 


\subsection{Determinants of forest extraction}

In Table 3 results of $Z$ INNB $^{13}$ model are presented. The data used in the estimation of the model revealed no significant sign of multi-collinearity. Factor changes are estimated along with the model coefficients in order to make the interpretation of parameter estimates easier (see Long and Freese, 2001). ${ }^{14}$ The model results consist of two subsets of parameter estimates. As indicated in Table 3 these coefficients include the logit and the NBRM equations of the ZINB model. The signs of the estimated coefficients carry differing interpretations between the two equations. A plus sign to an estimated coefficient in the logit equation implies an increase in the likelihood of no forest extraction whereas the same sign in the NBRM reflects a rise in the expected count of forest extraction trips. Referring to the results in Table 3, subjective discount rate (TM) and coefficient of variation of coffee income (CV_C) have negative and statistically significant effects on the odds of being in the always no forest extraction. In other words, a household in the sample is more likely to make forest extraction trips as values of these explanatory variables increase. For instance, a one-unit rise in the value of the $\mathrm{CV}$ _C variable reduces the odds always making zero forest extraction trips by a factor of about 0.9 . On the other hand, household perception of price risk to coffee beans (PR_R) exerts a significant positive effect on the likelihood of having no extraction trips.

\footnotetext{
${ }^{13}$ As a priori identification of the appropriate model for an event count data is often difficult, several variants of an event count model such as the Poisson, Zero-inflated Poisson, Negative binomial regression models were tried besides the ZINB model, with STATA 8.0. These models were compared and contrasted using several criteria of goodness of fit. In particular, validation tests using Akaike's information criterion (AIC), Bayesian information criterion (BIC) and log-likelihood function at convergence favour the ZINB model over others. Moreover, the ZINB model has passed two further tests. First, the Vuong-statistic $\left(\begin{array}{ll}V & =3.39\end{array}\right)$ is positive and significant at less than one percent probability indicating the rejection NBRM in favor of the ZINB model. Second, the dispersion parameter $(\alpha)$ is statistically significant and positive, after the excess zero issue is addressed, indicating the presence of over-dispersion in the data, in turn favoring a ZINB model rather than a ZIP model.

${ }^{14}$ As a priori identification of the appropriate model for an event count data is often difficult, several variants of an event count model such as the Poisson, Zero-inflated Poisson, Negative binomial regression models were tried besides the ZINB model, with STATA 8.0. These models were compared and contrasted using several criteria of goodness of fit. In particular, validation tests using Akaike's information criterion (AIC), Bayesian information criterion (BIC) and log-likelihood function at convergence favour the ZINB model over others. Moreover, the ZINB model has passed two further tests. First, the Vuong-statistic $\left(\begin{array}{lll}V & =3.39\end{array}\right)$ is positive and significant at less than one percent probability indicating the rejection NBRM in favor of the ZINB model. Second, the dispersion parameter $(\alpha)$ is statistically significant and positive, after the excess zero issue is addressed, indicating the presence of over-dispersion in the data, in turn favoring a ZINB model rather than a ZIP model.
} 
The estimated results indicate that five explanatory variables are statistically significant $(p \leq 0.10)$

to explain the count of forest extraction trips taken by households. Consistent with a priori expectation, the coefficient of variation of coffee income (CV_C), a proxy for riskiness of coffee farming, has a statistically significant and positive impact on the expected count of forest extraction trips taken by the households in the sample. More particularly, an increase in the volatility (i.e. a decrease in reliability) of income from coffee farming significantly contributes to an increase in household labour allocated to forest extraction in the study areas. For instance, a unit increase in the coefficient of variation of coffee income raises the expected number of forest extraction trips by a factor of 1.06 . This supports the assumption that coffee farmers are risk averse and that they increase their labor use in forestry to deal with coffee income risk ex ante.

Consistent with economic theory and our anticipation, the estimated results reveal that household forest extraction trip is strongly driven by undesirable income shocks facing coffee households (SHK_C) in the study areas. Specifically, forest extraction appeared to increase with the size of adverse income that faced many coffee farmers in 2001/02. For instance, for a unit increase in SHK_C variable, the expected number of forest extraction trips increases by a factor very close to one. The implication of this is that forests found in economically vulnerable areas are also vulnerable to human impacts since they are drawn upon to make up for shocks. In other words, these results provide evidence that forest extraction affords insurance to coffee farmers in the montane forest regions of southwest Ethiopia.

The results of this study also indicate that the effect of household size (FAMSZ) on the expected count of forest extraction trips is statistically significant and positive. The expected count of forest extraction trips increases by a factor of about 1.1 as the size of the household increases by one member. This suggests that, ceteris paribus, large households are likely to take more forest extraction trips than small households. The results also show that the frequency of forest extraction was positively and significantly associated with the respondents' rate of private time preferences (TM). ${ }^{15}$ This is consistent with the theoretical prediction and results reported by Gunatilake and Chakravorty (2003). Controlling for other differences, households with larger private discount rates have higher expected count of forest extraction trips than their colleagues with smaller private discount rates. This is congruent with the theoretical arguments that when the decision maker values the present more than the future; and

\footnotetext{
${ }^{15}$ Factor change in expected count for unit increase in $\mathrm{x}$ is computed as exp (b). In other words, an increase in $\mathrm{x}$ would multiply the fitted mean forest extraction trip by the exp (b).
} 
activities differ in their pay-back periods, a household with a relatively higher rate of time preference participates on the activity that generates more immediate returns to its effort. In the context of the present study, coffee farmers' labor allocation to forest extraction yields immediate returns while labor used in the wet-season in coffee agriculture waits until harvest to get returns.

Contrary to the a priori expectation, native households appear to more frequently participate in a forest extraction than non-natives to smooth consumption against adverse income shocks. The unexpected effect of the variable BIRTH on household forest extraction trips may be accounted for by two facts. In the first place, non-natives may be less familiar with forest-based livelihood or risk coping strategies. As such, these households might view the insurance value of forests as less important. Second, non-natives may be more likely to have received economic support, when a misfortune strikes, from relatives or friends who remained in the migrants' place of origin.

Table 4 indicates the sensitivity of forest extraction trips to changes in values of explanatory variables that are statistically significant. The predicted number of forest extraction trips increases by about twenty four percent and three percent if risk involved in coffee income and short-term shock (coffee income loss), respectively, facing the typical coffee-growing household increases by ten percent. Similarly, a ten percent rise in household size induces about five percent rise in the expected count of forest extraction trips in the study areas.

The statistically non-significant effects obtained for the other explanatory variables used in the econometric analysis are as follows. Notably, the coefficients to landholding (LAND) and cattle ownership (CATT) variables, which are key measures for wealth, are negative as expected but their effects are not statistically significant. Similarly, the effects of crop diversification (DIVSN), off-farm wage employment in the previous season (OFF), the distance from nearest all-weather road (DISR), membership to farmers' cooperative (COOP) and education $(\mathrm{EDUCHH})$ on forest extraction were, as anticipated, negative but again their impacts were not statistically significant. Conversely, the influences of the district dummy (LOCA), age of the household head (AGEHH) and male headship of the household (SEXHH) on forest extraction were positive. However, their impacts were not statistically significant.

\section{Conclusions and policy implications}

This paper has examined household labor supply responses via forest extraction as insurance against adverse coffee income. The estimated results show that households facing a high variability of coffee income are more likely to draw on forest resources to 
protect their welfare against risk. This study has also revealed that forest extraction increases further as magnitude of adverse coffee income shock confronting households in the sample increases in the study areas. Therefore, it is essential that the Ethiopian government, non-governmental organizations, local and international donors, etc. give particular attention to coffee income risk facing smallholder coffee farmers so as to facilitate its strong management under farmers' conditions and circumstances. Along this, ex post risk coping is crucial to survival of smallholder farmers, since, in agriculture, undesirable decision outcomes are the norm rather than the exception. More importantly, the development of contingency markets and safety net programs may be useful mechanisms to lessen household vulnerability to consumption shortfalls and also to take pressure off the forests following adverse income shocks. Public-work programs in the form of work-for-food or work-for-cash schemes might be useful means in this regard, to reduce the impact of risk on people and to redirect labor away from forest extraction.

The survey evidence also reveals that for any given level of income shortfall, households with high time preference are more likely to both participate in and draw more intensively on forest extraction. This suggests that forest extraction as a safety net is more pronounced among the poor households who lack liquidity when misfortune strikes. Thus, designing policies that in one way or the other reduce farmers' liquidity constraints would help lessen forest pressure. Such policies would include government investments in the provision of off-farm enterprises, technical education and infrastructural developments to improve access to wage employment, and other services such as markets and credits.

Similarly, forest extraction as a safety net among the survey participant households appears to be more pronounced with indigenous households than non-natives. Thus, policy interventions and incentive provisions need to be cognizant of differences in demographic history and associated socioeconomic behaviors among the local population. The other important demographic feature that would condition incentives for the reduction of forest extraction is the size of the household. Controlling for other explanatory variable, it was found that forest extraction effort was significantly higher among larger households than the smaller ones. On this point, it may be said, therefore, that policy measures aimed at reducing rapid population growth or fertility could contribute to the slowing down of the currently observed forest extraction pressure in the study areas.

In a nutshell, this paper confirms the risk mitigation role of the montane forests to smallholder coffee farmers in southwest Ethiopia Thus, policies which stimulate and enable farmers to hold on successful risk management and risk coping mechanisms 
would (i) protect farmers' welfare from likely crop income shortfalls and (ii) reduce household pressure on forests as a safety net such that forest degradation and biodiversity loss as a consequences of human action will decline over time. 


\section{References}

Agrisystems Limited. 2001. Coffee Support Project, Ethiopia: Formulation Report July 2001. Agrisystems House, United Kingdom.

Alderman, H. \& Paxson, C. 1992. Do the Poor Insure? World Bank Working Paper Series 1008, Washington, Dc.

Anderson, J. R., \& Dillon, J. L. 1992. Risk Analysis in Dryland Farming Systems, Management Series No. 2, Food and Agriculture Organization of the United Nations, Rome, Italy.

Baland, J. M., \& Francois, P. 2005. Commons as Insurance and the Welfare Impact of Privatisation. Journal of Public Economics, 89, pp. 211-31.

Beshir, A. Y. 2002. The Economics of Deforestation: The Case of Keffa Zone, Ethiopia'. M.Sc Thesis, Wageningen University.

Byron, N., and Arnold, M. 1999. What Features for the People of the Tropical Forests? World Development, 27(5), pp. 789-805.

Cameron, A. C., and Trivedi, P. K. 1998. Regression Analysis of Count Data. New York: Cambridge University Press.

de Janvry, A., Fafchamps, M. and Sadoulet, E. 1991. Peasant Household Behaviour with Missing Markets: Some Paradoxes Explained. The Economic Journal, 101, pp. 1400-17.

Dercon, S. 2002. Income Risk, Coping Strategies, and Safety Nets. The World Bank Research Observer, 17(2), pp. 141-66.

Ellis, F. 1998. Survey Article: Household Strategies and Rural Livelihood Diversification. Journal of Development Studies, 35(1), pp. 1-38.

1993. Peasant Economics: Farm Household and Agrarian Development, Second Edition, Cambridge, Cambridge University Press.

Fisher, M. and Shively, G. 2003. Do Tropical Forests Provide a Safety Net? Income Shocks and Forest Extraction in Malawi, Paper Prepared for the American Agricultural Economics Association Meeting 27-30 July 2003, Montreal.

Godoy, R. and Bennett, C. P. A. 1991. The Economics of Monocropping and Intercropping by Smallholders: The Case of Coconuts in Indonesia. Human Ecology, 19, pp. 83-98.

Goodwin, B. K. and Kastens, T. L. 1996. Analysis of Marketing Frequency by Kansas Crop Producers. Review of Agricultural Economics, 18, pp. 575-84.

Haab, T. C. and McConnel, K. E. 1996. Count Data Models and the Problem of Zeros in Recreation Demand Analysis. American Journal of Agricultural Economics, 78, pp. 89-102.

Holden, S., Bekele, S. and Wilk, M. 1998. Poverty, Market Imperfection, and Time Preference: Of Relevance for Environmental Policy. Environment and Development Economics, 3, pp. 105-30.

ICO (International Coffee Organization). 2004. Development Strategy for Coffee, Executive Board 254th Meeting. 29-30 January 2004, London, England.

Jacoby, H. and Skoufias, E. 1997. Risk, Financial Markets and Human Capital in a Developing Country. Review of Economic Studies, 64(1), pp. 311-35.

Jodha, N. S. 1986. Common Property Resources and Rural Poor in Dry Regions of India. Economic and Political Weekly, 21, pp. 1169-81. 
Kochar, A. 1999. Smoothing Consumption by Smoothing Income: Hours-of-work Responses to Idiosyncratic Agricultural Shocks in Rural India. The Review of Economics and Statistics, 81(1), pp. 50-61.

Lamb, R. L. 2003. Fertilizer Use, Risk, and Off-farm Labor Markets in the Semi-arid Tropics of India. American Journal of Agricultural Economics, 85(2), pp. 359-71.

Maitra, P. 2001 Is Consumption Smooth at the Cost of Volatile Leisure? An Investigation of Rural India. Applied Economics, 33, pp. 727-34.

Melkersson, M. and Rooth, D. 2000. Modeling Female Fertility Using Inflated Count Data Models. Journal of Population Economics, 13, pp. 189-203.

Ministry of Natural Resources Development and Environmental Protection. 1994. The Ethiopian Forest Action Plan. Addis Ababa, Ethiopia.

Oxfam. 2002. Mugged: Poverty in Your Cup, Oxfam International, London.

Pattanayak, S. K. and Sills, E. O. 2001. Do Tropical Forests Provide Natural Insurance? The Microeconomics of Non-timber Forest Product Collection in the Brazilian Amazon. Land Economics, 77, pp. 595-612.

Ponte, S. 2002. The Latte Revolution? Regulation, Markets and Consumption in the Global Coffee Chain. World Development, 30, pp. 1099-1122.

Reardon, T. and Vosti, S. A. 1995. Links between Rural Poverty and the Environment in Developing Countries: Asset Categories and Investment Poverty, World Development, 23, pp. 1495-1506.

Reusing, M. 1998. Monitoring of Natural High Forests in Ethiopia. Ministry of Agriculture and GTZ, Addis Ababa, Ethiopia.

Rose, E. 2001 Ex ante and Ex post Labour Supply Response to Risk in a Low-income Area. Journal of Development Economics, 64, pp. 371-88.

Rosenzweig, M. and Wolpin, K. 1993. Credit Market Constraints, Consumption Smoothing, and the Accumulation of Durable Production Assets in Low Income Countries: Investment in Bullocks in India. Journal of Political Economy, 101, pp. 223-44.

Rosenzweig, M. R. 1988. Risk, Implicit Contracts and the Family in Rural Areas of Low- income Countries. Economic Journal, 98(393), pp. 1148-70.

Rosenzweig, M. R. and Stark, O. 1989. Consumption Smoothing, Migration, and Marriage: Evidence from Rural India. Journal of Political Economy, 97, pp. 905-26.

Ruben, R. and Masset, E. 2003. Land Markets, Risk and Distress Sales in Nicaragua: The Impact of Income Shocks on Rural Differentiation. Journal of Agrarian Change, 3(4), pp. 481-99.

Shiferaw, G. and Trivedi, P. K. 1996. Excess Zeros in Count Data Models for Recreational Trips. Journal of Business and Economic Statistics, 14(4), pp. 469-77.

Singh, I., Squire, L. and Strauss, J. (eds.). 1986. Agricultural Household Models. Baltimore, Md: The Johns Hopkins University Press.

Tadesse, W. G., Denich, M., Demel, T. and Vlek, P. 2001. Human Impacts on the Coffea arabica genepool in Ethiopia and the need for its in Situ Conservation. In: Engels, J., Ramanatha, R. V., Brown, A., \& Jackson, M. (eds.), Managing Plant Genetic Diversity. CAB International.

Takasaki, Y., Barham, B. L. and Coomes, O. T. 2004. Risk Coping Strategies in Tropical Forests: Floods, Illnesses, and Resource Extraction. Environment and Development Economics, 9(2), pp. 203-24. 
Udry, C. 1995. Risk and Saving in Northern Nigeria. American Economic Review, 85(5), pp.1287-1300.

Vakis, R., Kruger, D. and Mason, A. D. 2004. Shocks and Coffee. World Bank Social Protection Discussion Paper Series, Washington, Dc.

Varangis, P., Siegel, P. Giovnnucci, D. and Lewin, B. 2003. Dealing with the Coffee Crisis in Central America: Impacts and Strategies. World Bank Policy Research Working Paper Series 2993, Washington, DC.

Wong, G. Y. and Godoy, R. 2003. Consumption and Vulnerability among Foragers and Horticulturalists in the Rainforest of Honduras. World Development, 31, pp. 1405-19.

World Bank. 2002. Development Goals. Washington, DC, World Bank. Available at http://www.developmentgoals.org/findout-acieving.html (Retrieved on December 2004). 
Table 1: Summary statistics and definitions of explanatory variables

\begin{tabular}{|c|c|c|c|}
\hline Variables & Definition and measurement & Mean & Std.dev. \\
\hline AGEH & age of the household head in years & 44.31 & 13.92 \\
\hline SEXH & $\%$ male-headed respondents & 90.0 & 0.29 \\
\hline EDUCH & $\%$ literate respondents & 47.0 & 0.50 \\
\hline FAMSZ & total number of members in the household & 5.67 & 2.29 \\
\hline$A D \_F$ & number of adult females in the household & 1.53 & 0.83 \\
\hline$A D \_M$ & number of adult males in the household & 1.62 & 1.04 \\
\hline BIRTH & $\%$ native households & 0.76 & 0.43 \\
\hline LAND & landholding in ha & 2.36 & 1.66 \\
\hline LOCA & $\%$ households located in Yayu & 59.0 & 0.49 \\
\hline TM & subjective discount rate, $1=$ low, $2=$ medium, $3=$ high & 2.03 & 0.78 \\
\hline CATT & number of cattle holding & 2.76 & 2.94 \\
\hline CV_C & coefficient of variance of income from coffee & 39.75 & 4.48 \\
\hline SHK_C & adverse income shock to coffee in 2001/02 in Birr & 1619.0 & 1710.0 \\
\hline DISF & distance to the nearest forest in minutes & 51.19 & 33.39 \\
\hline DISR & distance to nearest all weather road in minutes & 20.69 & 21.46 \\
\hline OFF & $\%$ with wage income in the dry season of $2001 / 02$ & 34.0 & 0.47 \\
\hline PR_R & $\begin{array}{l}\text { perceived coffee price risk, with } 1 \text { not important to } 5 \text { very } \\
\text { important }\end{array}$ & 3.91 & 1.24 \\
\hline DIVSN & number of crop enterprises & 2.84 & 1.64 \\
\hline COOP & $\%$ with membership to farmers' cooperative & 55.0 & 0.49 \\
\hline
\end{tabular}

Source: Own survey data, 2001/02.

Table 2: Farmers' perception of importance of risk coping strategies

\begin{tabular}{lcr}
\hline \multicolumn{1}{c}{ Type of strategy } & $\begin{array}{c}\text { Number of respondents who } \\
\text { considered strategy as } \\
\text { important or very important }\end{array}$ & $\begin{array}{c}\text { Percent of } \\
\text { total }\end{array}$ \\
\hline Forest extraction & 118 & 61 \\
Out-migration to cities & 17 & 9 \\
Credit from friends & 129 & 66 \\
Reducing food consumption & 113 & 58 \\
Food aid & 118 & 61 \\
Drawing on household savings & 132 & 68 \\
Livestock sales & 144 & 74 \\
Remittances & 109 & 56 \\
Pulling out children from school to work & & 11 \\
\hline Source: Own survey, 2001/02 & 21 &
\end{tabular}

Source: Own survey, 2001/02. 
Table 3: ZINB Regression Coefficients of Forest Extraction Frequency

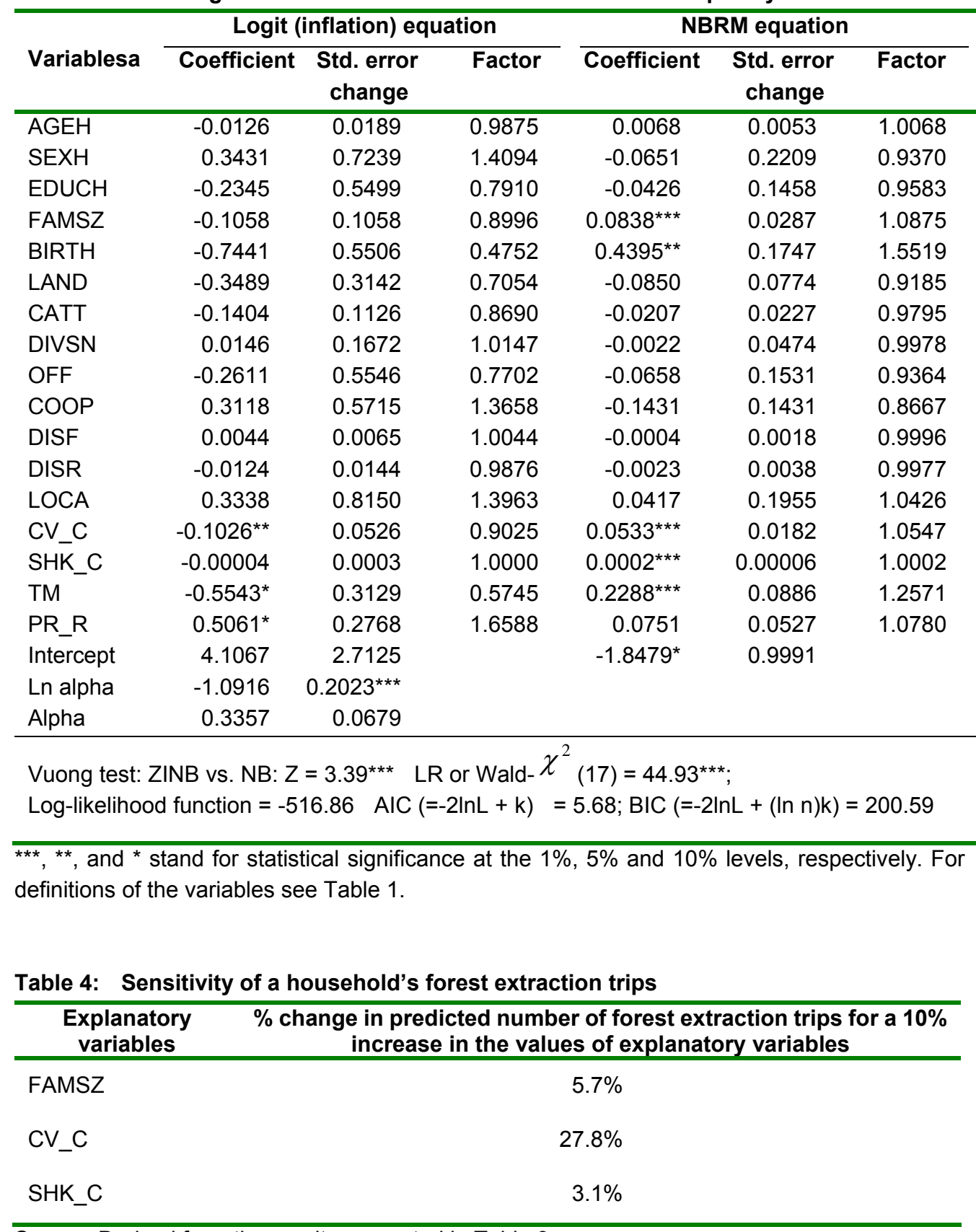

Source: Derived from the results presented in Table 3. 
